\title{
Институциональный параметр "силы" региональных отделений всероссийских партий в Дальневосточном федеральном округе
}

Несмотря на тот факт, что партии в регионах России получили свою прописку относительно давно, их роль в политическом процессе далеко не везде однозначна. Это объясняется не только социально-экономическими факторами, но и особенностями конфигурации региональных органов власти. Несмотря на фракт существования целого ряда рамочных законов, регулирующих механизм формирования органов власти сам формат от случая к случаю значительно, отличается.

Цель данной работы заключается сборе и сравнении данных показателей "силы" региональных отделений всероссийских партий Дальневосточного Федерального Округа (ДФО). На основе полученных данных мы предполагаем, что сможем определить, в каком из регионов ДФО будет протекать самая острая идеологическая борьба за мандаты депутатов Госдумы нынешней осенью. При этом на данный момент мы будем исходить из формальных критериев, фриксируя номинальную "силу партий" в субъектах фредерации ДФО.

Партии, явившиеся инструментом, сглаживающим острые углы в отношениях центра и регионов, при этом порождают совершенно разные принципы лоббирования интересов в обе стороны. В каждом регионе они свои, именно поэтому наш индекс "силы партии", как мы считаем, позволит хотя бы номинально определить насколько важно для того или иного региона ДФО идеологическое распределение мест в региональной системе власти. Таким образом "сила партии" определяется нами как номинальная оценочная совокупность полномочий, которые получает та или иная партия в том или ином регионе России, исходя из текущей расстановки политических сил, которую можно отследить.

За основу нами берутся данные не только расстановки сил в региональном парламенте, но и учитывается партийная принадлежность главы региона, депутатов федерального собрания, назначенных и избранных от субъекта федерации.

Количественные исследования политических партий являются довольно широко охваченной темой исследований в России $[8$, с. 29-51; 9, с. 27-49; 22, с. 134-142]. Наш подход к анализу во многом еще более прост и вписывается в классические принципы институционального анализа. Важным достоинством параметра "силы партии" является учет всех возможных постов как исполнительных, так и в законодательных органах власти как в самом регионе, так и его представителей на уровне фредерального центра.

\section{Методика проведения исследования}

В качестве методики исследования "силы" политических партий мы за основу используем широко известный подход М.С. Шугарта и Дж. Кэри. Данная методика предполагает использование простого интервального метода. Разделив полномочия президента на законодательные и незаконодательные, Шугарт и Кэри оценивают каждое из них по 5-балльной системе $(4-3-2-1-0)$, а затем суммируют полученные числовые значения [23, c. 148-166]. Выделение "не целых" чисел обуславливается тем обстоятельством, что часть полномочий последних условно можно назвать "половинчатыми" [6, с. 9].

(C) Будаев Б. С., 2021

БУДАЕВ Батор Солбонович, к.полит.н., доцент кафедры политологии и социологии Бурятского государственного университета им. Д. Банзарова (2. Улан-Удэ). E-mail: brotabs83@mail.ru 
Таблица 1. Распределение должностных позиций в регионе согласно рейтингу "силы"

\begin{tabular}{|c|l|c|}
\hline & \multicolumn{1}{|c|}{ Название органа власти (должности) } & Рейтинг в баллах \\
\hline 1 & Зам. пред. комитета в региональном законодательном собрании & 0,5 \\
\hline 2 & Председатель комитета в региональном законодательном собрании & 1,0 \\
\hline 3 & Зам. пред. регионального законодательного собрания & 1,5 \\
\hline 4 & Председатель регионального законодательного собрания & 3,0 \\
\hline 5 & Депутат Совета Федерации от региона & 1,5 \\
\hline 6 & Депутат Государственной Думы от региона & 2,0 \\
\hline 7 & Глава субъекта фредерации & 4,5 \\
\hline
\end{tabular}

Источник: составлено автором.

Мы в данном случае будем распределять наиболее важные с точки зрения партийной принадлежности выборные и назначаемые должности в региональном политическом пространстве. Вопрос расстановки баллов "силы" партийных игроков в региональном политическом пространстве нами определяется согласно таблице 1.

Ключевыми отправными точками для определения "силы" партийных игроков в региональном пространстве, безусловно, стали фригуры главы региона и спикера регионального парламента. Априори в большинстве сегодняшних регионов глава субъекта "сильнее" спикера, что обуславливается его прямой формой ответственности перед населением, в то время как спикер отвечает, в-первую очередь, перед парламентом, затем перед жителями территории, от которой он избран (либо партии, если избран по пропорциональной части) [7, с. 146-164].

Соответственно для определения "силы" главы субъекта правильнее станет процесс разложения должностных полномочий в рамках парламента. В результате за одну единицу "силы" будет взят статус главы комитета в региональном законодательном собрании. Исходя из сложившейся ситуации, распределение становится, по нашему мнению, вполне объективным.

Совет Федерации сегодня по целому ряду параметров является органом власти в рамках которого партийная принадлежность уходит на второй план. Именно поэтому его оценка партийной составляющей чуть меньше, чем депутатов Госдумы. Ввиду чрезвычайной удаленности Москвы параметры оценки влияния депутатов Госдумы в регионе также низки [21, с. 162-180] и составляют 2 балла.

Безусловно, сам вопрос расстановки баллов во многом обсуждаемый, но учитывая реальную характеристику органов власти, данные в таблице №1 мы считаем реально объективными.

Не менее важными для учета качества партийного соревнования на местах мы считаем характеристики повышающего коэффициента, обусловленные параметрами инкумбентства [3, с. 14]. Но в данном случае их необходимо разделить. В случае с главой субъекта федерации, депутатов федерального собрания, максимально повышающий коэффрициент мы будем определять из расчета: сохранения статуса депутата - это умножение их возможностей в 1,5 раза, в случае если действующий представитель региона занимает это пост в первый раз, повышающий коэффрициент будет равен - 1. Расчет повышающих коэффициентов в процессе учета силы партий в рамках регионального парламента будет учитываться исходя из общей доли инкумбентов и расчета величины фрракции в региональном парламенте.

Суммируя, таким образом, полученные результаты, мы получим количественный показатель силы каждой из партий. Исходя уже из полученных данных, мы сможем определить, каков процент влияния каждой из партии в процессе принятия политических решений в регионе. 


\begin{tabular}{|c|c|c|c|c|c|c|c|c|c|}
\hline & Регионы & 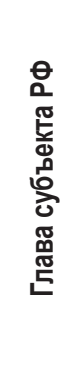 & 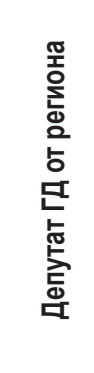 & 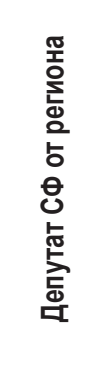 & 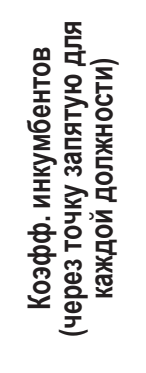 & 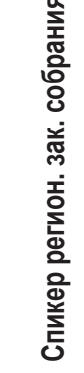 & 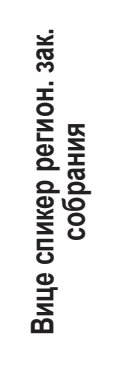 & 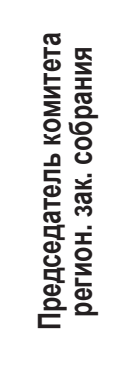 & 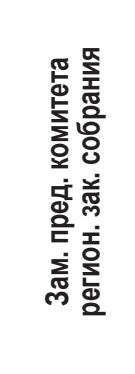 \\
\hline 1 & $\begin{array}{l}\text { Амурская } \\
\text { область }\end{array}$ & EP & $\begin{array}{l}\text { 1) ЛДПР } \\
\text { 2) СР }\end{array}$ & $\begin{array}{l}\text { 1) } \mathrm{EP} \\
\text { 2)ЛДПР }\end{array}$ & $1 ; 1 ; 1 ; 1,5 ; 1$ & EP & $\begin{array}{l}\text { 1) } \mathrm{EP} \\
\text { 2) } \mathrm{EP}\end{array}$ & 1) $5 \mathrm{EP}$ & $\begin{array}{l}\text { 1) } К П Р Ф \\
\text { 2) } \mathrm{EP} \\
\text { 3) } \mathrm{CP} \\
\text { 4) ЛДПР } \\
\text { 5) - }\end{array}$ \\
\hline 2 & $\begin{array}{l}\text { Хабаровский } \\
\text { край }\end{array}$ & ЛДПР & $\begin{array}{l}\text { 1) ЛДПР } \\
\text { 2) } \mathrm{EP}\end{array}$ & $\begin{array}{l}\text { 1) ЛДПР } \\
\text { 2) ЛДПР }\end{array}$ & $1 ; 1 ; 1 ; 1$ & ЛДПР & $\begin{array}{l}\text { 1) ЛДПР } \\
\text { 2) } \mathrm{EP}\end{array}$ & 1) 5 ЛДПР & 5 ЛДПР \\
\hline 3 & Приморский край & EP & $\begin{array}{l}\text { 1) ЛДПР } \\
\text { 2) КПРФ } \\
\text { 3) } \mathrm{EP} \\
\text { 4) } \mathrm{EP} \\
\text { 5) } \mathrm{EP} \\
\text { 6) } \mathrm{EP}\end{array}$ & $\begin{array}{l}\text { 1) } \mathrm{EP} \\
\text { 2) } \mathrm{CP}\end{array}$ & $\begin{array}{l}1 ; 1 ; 1,5 ; 1 ; 1 ; \\
1 ; 1,5 ; 1 ; 1,5\end{array}$ & EP & $\begin{array}{l}\text { 1) } \mathrm{EP} \\
\text { 2) } \mathrm{EP}\end{array}$ & $\begin{array}{l}\text { 1) } 5 \text { ЕР } \\
\text { (1 совмест) } \\
\text { 2) } 1 \text { ЛДПР }\end{array}$ & $\begin{array}{l}\text { 1) } 12 \mathrm{EP} \\
\text { 2) } 4 \text { КПРФ } \\
\text { 3) } 1 \text { ЛДПР } \\
\text { 4) } 1 \mathrm{CP}\end{array}$ \\
\hline 4 & $\begin{array}{l}\text { Сахалинская } \\
\text { область }\end{array}$ & EP & EP & $\begin{array}{l}\text { 1) } \mathrm{EP} \\
\text { 2) } \mathrm{EP}\end{array}$ & $1 ; 1,5 ; 1 ; 1$ & EP & EP & 1) $6 \mathrm{EP}$ & $\begin{array}{l}\text { 1) } 8 \text { ЕР } \\
\text { 2) } 3 \text { КПРФ } \\
\text { 3) } 1 \text { ЛДПР }\end{array}$ \\
\hline 5 & $\begin{array}{l}\text { Еврейская авто- } \\
\text { номная область }\end{array}$ & EP & EP & $\begin{array}{l}\text { 1) Б/п } \\
\text { (Валяев } \\
\text { Ю.К.) } \\
\text { 2) EP }\end{array}$ & $1 ; 1 ; 1 ; 1,5$ & EP & EP & $\begin{array}{l}\text { 1) } 5 \text { EP } \\
\text { (1 совмест) }\end{array}$ & $\begin{array}{l}\text { 1) } 5 \text { ЕР } \\
\text { 2) } 1 \text { ЛДПР } \\
\text { 3) КПРФ } \\
\text { 4) СР }\end{array}$ \\
\hline 6 & $\begin{array}{l}\text { Магаданская } \\
\text { область }\end{array}$ & EP & EP & $\begin{array}{l}\text { 1) } \mathrm{EP} \\
\text { 2) } \mathrm{EP}\end{array}$ & $1 ; 1 ; 1,5 ; 1,5$ & EP & $5 \mathrm{EP}$ & $\begin{array}{l}3 \text { EP } \\
\text { (2 совмест) }\end{array}$ & $3 \mathrm{EP}$ \\
\hline 7 & Камчатский край & EP & $\begin{array}{l}\text { 1) } \mathrm{EP} \\
\text { 2) } \mathrm{EP}\end{array}$ & $\begin{array}{l}\text { 1) } \mathrm{EP} \\
\text { 2) } \mathrm{EP}\end{array}$ & $1 ; 1,5 ; 1,5 ; 1$ & EP & $2 \mathrm{EP}$ & $\begin{array}{l}4 \text { ЕР } \\
\text { (1 совмест) }\end{array}$ & $\begin{array}{l}\text { 1) } 8 \mathrm{EP} \\
\text { 2) } 1 \text { ЛДПР } \\
\text { 3) } 1 \text { КПРФ }\end{array}$ \\
\hline 8 & $\begin{array}{l}\text { Чукотский авто- } \\
\text { номный округ }\end{array}$ & EP & EP & $\begin{array}{l}\text { 1) } \mathrm{EP} \\
\text { 2) } \mathrm{EP}\end{array}$ & 1,$5 ; 1 ; 1,5 ; 1,5$ & EP & $2 \mathrm{EP}$ & $\begin{array}{l}4 \text { EP } \\
\text { (2 совмест) }\end{array}$ & $\begin{array}{l}\text { 1) } 3 \mathrm{EP} \\
\text { 2) } 1 \mathrm{CP}\end{array}$ \\
\hline 9 & $\begin{array}{l}\text { Республика } \\
\text { Бурятия }\end{array}$ & EP & $\begin{array}{l}\text { 1) } E P \\
\text { 2) } E P\end{array}$ & $\begin{array}{l}\text { 1) } E P \\
\text { 2) } E P\end{array}$ & $1 ; 1 ; 1 ; 1 ; 1,5$ & EP & $2 \mathrm{EP}$ & $\begin{array}{l}\text { 1) } 5 \mathrm{EP} \\
\text { 2) } 1 \mathrm{~K} П \mathrm{P \Phi}\end{array}$ & $\begin{array}{l}\text { 1) } 3 \mathrm{EP} \\
\text { 2) } 1 \mathrm{КПРФ} \\
\text { 3) } 1 \text { ЛДПР } \\
\text { 4) } 1 \mathrm{CP}\end{array}$ \\
\hline 10 & $\begin{array}{l}\text { Забайкальский } \\
\text { край }\end{array}$ & EP & $\begin{array}{l}\text { 1) КПРФ } \\
\text { 2) ЛДПР } \\
\text { 3) } \mathrm{EP}\end{array}$ & $\begin{array}{l}\text { 1) } E P \\
\text { 2) } E P\end{array}$ & $\begin{array}{l}1 ; 1,5 ; 1,5 ; 1,5 \\
1 ; 1,5\end{array}$ & EP & $3 \mathrm{EP}$ & $\begin{array}{l}\text { 1) } 5 \text { ЕР } \\
\text { (3 совмест) } \\
\text { 2) } 1 \text { ЛДПР }\end{array}$ & $\begin{array}{l}\text { 1) } 1 \text { ЕР } \\
\text { 2) } 1 \text { КПРФ } \\
\text { 3) } 1 \mathrm{CP} \\
\text { 4) } 1 \text { ЛДПР } \\
\text { 5) } 1 \text { Партия } \\
\text { пенсионеров } \\
\text { 6) } 1 \text { Партия } \\
\text { дела }\end{array}$ \\
\hline 11 & $\begin{array}{l}\text { Республика Саха } \\
\text { Якутия }\end{array}$ & EP & $\begin{array}{l}\text { 1) } \mathrm{EP} \\
\text { 2) } \mathrm{CP}\end{array}$ & $\begin{array}{l}\text { 1) } E P \\
\text { 2) } E P\end{array}$ & $1 ; 1 ; 1,5 ; 1 ; 1,5$ & EP & $\begin{array}{l}\text { 1) } 2 \mathrm{EP} \\
\text { 2) } 1 \mathrm{~K} \mathrm{PФ}\end{array}$ & $\begin{array}{l}\text { 1) } 11 \mathrm{EP} \\
\text { 2) } 1 \text { ЛДПР } \\
\text { 3) } 1 \mathrm{CP}\end{array}$ & $\begin{array}{l}\text { 1) } 17 \mathrm{EP} \\
\text { (2 совмест) } \\
\text { 2) } 2 \text { ЛДПР } \\
\text { 3) } 2 \mathrm{KПРФ} \\
\text { 4) } 1 \mathrm{CP}\end{array}$ \\
\hline
\end{tabular}

Источник: составлено автором на основе: [1, с. 83-96; 2, с. 48-59; 4; 5; 10; 11; 12; 13; 14; 15; 16; $17 ; 18 ; 19 ; 20]$. 
Таблица 2. "Сила" политических партий в субъектах Дальневосточного федерального округа

\begin{tabular}{|c|c|c|c|c|c|c|c|c|c|c|}
\hline \multirow{3}{*}{ 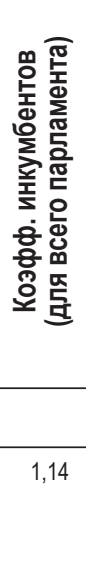 } & \multirow{3}{*}{ 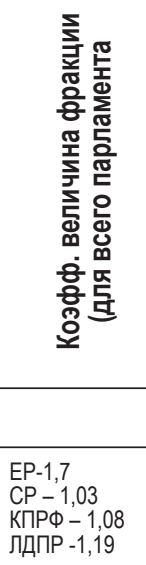 } & \multicolumn{8}{|c|}{$\begin{array}{c}\text { Сила партии в регионе } \\
\text { Первый столбец - сила политической партии. } \\
\text { Второй столбец - доля влияния партий } \\
\text { на процесс принятия политического решения в регионе }\end{array}$} & \multirow{3}{*}{$\frac{06 m}{36,38}$} \\
\hline & & \multicolumn{2}{|c|}{$E P$} & \multicolumn{2}{|c|}{ ЛДПР } & \multicolumn{2}{|c|}{ КПРФ } & \multicolumn{2}{|c|}{$C P$} & \\
\hline & & 29,037 & $79,81 \%$ & 4,1156 & $11,31 \%$ & 0,6156 & $1,69 \%$ & 2,6156 & $7,18 \%$ & \\
\hline 1 & $\begin{array}{l}\text { ЛДПР -1,78 } \\
\text { ЕР-1,083 } \\
\text { КПРФ-1,055 }\end{array}$ & 4,166 & $11,61 \%$ & 30,86 & $86,05 \%$ & & & & & 35,86 \\
\hline 1,375 & $\begin{array}{l}\mathrm{EP}-1,6 \\
\text { КПРФ-1,2; } \\
\text { ЛДПР-1,125 } \\
\mathrm{CP}-1,025\end{array}$ & 52,4 & $79,42 \%$ & 4,32 & $6,54 \%$ & 6,3 & $9,54 \%$ & 2,9546 & $4,47 \%$ & 65,97 \\
\hline 1,32 & $\begin{array}{l}\text { ЕР-1,71 } \\
\text { КПРФ-1,1 } \\
Л Д П Р-1,07\end{array}$ & 43,224 & $93,74 \%$ & 0,7062 & $1,53 \%$ & 2,178 & $4,72 \%$ & & & 46,08 \\
\hline 1,42 & $\begin{array}{l}\mathrm{EP}-1,68 \\
\text { КПРФ-1,11 } \\
\text { ЛДПР-1,16 } \\
\text { СР-1,05 }\end{array}$ & 32,606 & 93,27 & 0,8236 & $2,35 \%$ & 0,7881 & $2,25 \%$ & 0,7455 & $2,13 \%$ & 34,95 \\
\hline 1,5714 & $\begin{array}{l}\mathrm{EP}-1,81 \\
\text { ЛДПР-1,09 } \\
\text { СР }-1,04 \\
\text { КПРФ } 1,04\end{array}$ & 53,66 & $100 \%$ & & & & & & & 53,6 \\
\hline 1,39 & $\begin{array}{l}\text { ЕР } 1,75 \\
\text { ЛДПР-1,11 } \\
\text { КПРФ- } 1,07\end{array}$ & 47,055 & $96,88 \%$ & 0,77145 & $1,58 \%$ & 0,74365 & $1,53 \%$ & & & 48,57 \\
\hline 1,2 & $\begin{array}{l}\mathrm{EP}-1,67 \\
\text { КПРФ-1,13 } \\
\text { ЛДПР-1,13 } \\
\text { СР- } 1,07\end{array}$ & 36,296 & $98,26 \%$ & & & & & 0,642 & $1,74 \%$ & 36,93 \\
\hline 1,45 & $\begin{array}{l}\text { EP- } 1,6 \\
\text { КПРФ }-1,15 \\
\text { СР-1,08 } \\
\text { ЛДПР- } 1,06\end{array}$ & 41,25 & $91,05 \%$ & 0,7685 & $1,69 \%$ & 2,5 & $5,51 \%$ & 0,783 & $1,72 \%$ & 45,30 \\
\hline 1,3 & $\begin{array}{l}\mathrm{EP}-1,42 \\
\text { КПРФ-1,28 } \\
Л Д П Р-1,2 \\
C P-1,06 \\
П П Р-1,02 \\
П Д-1,02\end{array}$ & 33,998 & $75,24 \%$ & 5,34 & $11,81 \%$ & 3,832 & $8,4 \%$ & 0,689 & $1,524 \%$ & 45,04 \\
\hline 1,4 & $\begin{array}{l}\text { ЕР-1,67 } \\
\text { КПРФ- } 1,14 \\
\text { СР }-1,12 \\
\text { ЛДПР- } 1,057\end{array}$ & 47,123 & $79,38 \%$ & 2,9596 & $4,98 \%$ & 3,92 & $6,60 \%$ & 5,352 & $9,01 \%$ & 59,36 \\
\hline
\end{tabular}


Полученные результаты параметров "силы партий", по-нашему мнению, должны отражать остроту идеологической борьбы, которая будет осуществляться в региональном политическом пространстве. Поскольку любой член партии, занимающий тот или иной пост, вынужден в той или иной мере демонстрировать свою приверженность к идеалам той силы, что он воплощает.

Результаты сбора данных предложены в таблице 2.

В качестве примера возьмем пример расчета параметров силы партии в Амурской области. Расчет "силы партии" ЕР: 4,5 (глава региона, член ЕР) + 1,5(депутат СФ, член ЕР) ×1,5 (поскольку занимает второй срок подряд) + (3(спикер, член ЕР) +1,5×2 (2 вице спикера члены ЕР) + 5 (председатели комитетов, члены ЕР) + 0,5 (зам.пред комитета, член ЕР)) $\times 1,14$ (доля инкумбентов в региональном законодательном собрании, составляет 14\%) $\times 1,7$ (величина фрракции ЕР составляет 70\%) =29,037. При расчете силы всех партий в регионе, мы определяем долю партии ЕР, которая составляет - 79,81\%. Такова доля влияния партийных функционеров, избранных на ключевые позиции в региональной системе органов государственной власти.

Полученные данные позволяют отметить, что наибольшими показателями "силы" партии в ДФО выделяются отделение ЕР в Магаданской области - 53,6, что обусловлено тем, что все мандаты от региона на уровне фредерации, как и пост главы субъекта заняли представители партии власти. В региональном парламенте целых пять вице-спикеров! Не маловажным стало и то, что самая большая фракция и самый большой показатель доли инкумбентов также характерен для партии "Единая Россия" в этом регионе.

На втором месте следует выделить отделение "партии власти" в Приморском крае -52,4-EР, что можно объяснить тем, что у края 6 депутатов Госдумы, а в региональном законодательном собрании целых 3 заместителя в постоянных комитетах регионального законодательного собрания.

Среди низких показателей "силы партии" следует отметить Амурскую область $(29,037$ - ЕР) и Хабаровский край (30,86 - ЛДПР). И если в Амурской области относительная слабость ЕР объясняется тем, что места в Федеральном Собрании получили депутаты оппозиционных партий, то в случае Хабаровского края с доминирующей ЛДПР понижающим фрактором является отсутствие инкумбентов.

Суммируя таким образом данные "силы" партий в регионе, мы можем определить, в каком из субъектов ДФО "идеологический" формат борьбы должен быть наиболее острым. Полученные данные позволяют распределить регионы в следующей последовательности: Приморский край $(65,9)$, Республика Саха Якутия (59,3), Магаданская область $(53,6)$, Камчатский край $(48,5)$, Сахалинская область $(46,08)$, Республика Бурятия $(45,3)$, Забайкальский край $(45,04)$.

Кроме номинальных показателей "силы партии", безусловно, необходимо учитывать и долю влияния той или иной силы на процесс принятия политических решений. В тех регионах, где доля доминирующей партии будет наименее значимой, логично следует предположить: будет усиливаться межпартийное соревнование, и как следствие идеологическая борьба. В результате последовательность регионов ДФО значительно изменяется. На первом месте в этом случае выходят: Забайкальский край $(75,24 \%$ - ЕР), Республика Саха (Якутия) (79,38\% - ЕР), Амурская область (79,81\% - ЕР), Приморский край $(79,42 \%)$, Хабаровский край $(86,05 \%$ - ЛДПР).

Учитывая абсолютную форму доминирования "партии власти" в Магаданской и Сахалинской областях и Камчатском крае, следует предположить, что в этих регионах острой идеологической борьбы не будет.

Полученные данные позволяют предположить, что, исходя из институциональных параметров, наиболее острая идеологическая борьба, на предстоящих думских выборах осенью 2021 г., будет реализована в Приморском крае, Республике Саха Якутия, Забайкальском крае, Амурской области и Хабаровском крае.

Проведенное сравнительное исследование вскрывает целый ряд формальных принципов развития региональных парламентов, которые нуждаются в дальнейшем изучении, поскольку посредством их либо усиливается, либо ослабляются институциональные качества региональных отделений 
всероссийских политических партий. И если до событий 2011 г. эти правила усиливали позиции "партии власти", то сейчас однозначного ответа на этот вопрос нет.

Так сегодня часть регионов уже перешла к новой схеме выборов парламентариев или готовится к ней перейти ${ }^{1}$, в рамках которой сокращается доля парламентариев избираемых по пропорциональной системе. Это, с одной стороны, ослабит партии на местах, с другой стороны, в условиях кризиса "партии власти" сможет усилить последнюю. Практически повсеместно в регионах России последние два электоральных цикла если победу одерживает "партия власти", то этого удается добиться исключительно за счет "мажоритарных округов".

Среди особых случаев ДФО, позволяющих нивелировать значение миноритарных фракций в регионах, следует, например, выделить 3 заместителя в комитетах законодательного собрания Приморского края. Но при этом есть обратные примеры, когда статус "партии власти" можно поднять за счет усиления позиций вице-спикеров, как это сделали в Магадане.

Выбивается из этой череды случай Саха Якутии с ее 15 постоянно действующими комитетами. При подсчете "силы" партий выявилось, что в ряде регионов часть депутатов имеют возможность работать в нескольких комитетах, но еще большее удивление вызывают случаи совмещения нескольких должностей одновременно. Так депутат Ил Тумэна (законодательного собрания Республики Саха (Якутии)) Михаил Дмитриевич Гуляев является председателем комитета по делам молодежи, физической культуре и спорту; заместителем председателя комитета по вопросам местного самоуправления и заместителем председателя комитета по науке, образованию, культуре, средствам массовой информации и делам общественных организаций.

Не менее важным является учет того фракта, что регламенты парламентов субъектов феедерации ДФО предполагают разные возможности занятия должностей. Так в случае с Забайкальским краем, регламент Законодательного собрания предполагает возможность получения должностей миноритарными фрракциями, как минимум это должности зам. председателя комитета. Именно благодаря этому обстоятельству парламентарии от партий "Пенсионеров", "Справедливой России" и "Партии дела" при численности даже в один депутат, получили пост зампреда комитета.

В заключении следовало отметить, что в исследуемых случаях подтверждаются данные, свидетельствующие о том, что наиболее конкурентной в идеологическом плане борьба становится в крупных по численности субъектах. Вместе с тем, как показывает исследование, стабильности можно достичь и путем институционального әкспериментирования.

\section{Литература}

1. Будаев Б.С. Бадмацыренов Т.Б. Политические партии "новых" субъектов Дальневосточного Федерального округа в преддверии начала нового электорального цикла" // Вестник ЗабГУ. 2021. Том 27. № 2. С. 83-96.

2. Будаев Б.С. Бадмацыренов Т.Б. Политические партии и "длинный электоральный цикл в Республике Бурятия 2016-2019 // Вестник ЗабГУ. 2020. Том 26. № 4. C. $48-59$.

3. Григорьева М.В. Участие региональных и муниципальных депутатов в выборах законодательных собраний субъектов РФ // Вестник Пермского университета. Серия: Политология. 2012. №3. С 13-28.

4. Депутаты Государственной Думы РФ [Электронный pecypc]. URL: http:// duma.gov.ru/duma/deputies/ (дата обращения: 03.04.2021).

5. Депутаты Совета Федерации РФ [Электронный ресурс]. URL: http://council. gov.ru/structure/members/ (дата обращения: 03.04.2021).

6. Зазнаев О.И. Измерение президентской власти // Ученые записки Казанского государственного университета. Гуманитарные науки. 2005. Том 147. кн. 1. С. 4-22.

7. Зазнаев О.И. Индексный анализ полупрезидентских государств Европы и постсоветского пространства // Полис. 2007. № 2. С. 146-164.

1 Прежняя схема предполагала выборы региональных парламентов по схеме 50\% по мажоритарным округам и 50\% по пропорциональной системе. Сейчас во многих регионах предлагается сократить долю парламентариев, избираемых по пропорциональной системе 
8. Исаев Б.А. Характеристики партийных систем и вычисление некоторых показателей партиом // ПОЛИТЭКС. 2016. № 1. С. 29-51.

9. Лейпхарт А. Партийные системы. Двухпартийные и многопартийные системы // Партии и выборы: Хрестоматия / РАН.ИНИОН. М.: ИНИОН, 2004. С. 28-31.

10. Сайт Государственного собрания Ил Тумән Республики Саха Якутия ГЭлектронный ресурc]. URL: https://iltumen.ru/deputies (дата обращения: 03.04.2021).

11. Сайт Думы Чукотского автономного округа [Электронный ресурс]. URL: https://xn--80ahnhajq6aec7b.xn--p1ai/deputaty.html (дата обращения: 03.04.2021).

12. Сайт Законодательного собрания Амурской области [Электронный ресурс]. URL: http://zsamur.ru/section/list/777/9 (дата обращения: 03.04.2021).

13. Сайт Законодательного собрания Еврейской автономной области [Электронный ресурc]. URL: http://zseao.ru/sostav-i-struktura-zs/deputaty-zakonodatelnogosobraniya-vi-sozyva/ (дата обращения: 03.04.2021).

14. Сайт Законодательного собрания Забайкальского края [Электронный реcypc]. URL: http://www.zaksobr-chita.ru/sostav-i-struktu-a/deputaty/ (дата обращения: 03.04.2021).

15. Сайт Законодательного собрания Камчатского края [Электронный ресурс]. URL: http://www.zaksobr.kamchatka.ru/events/Deputaty (дата обращения: 03.04.2021).

16. Сайт Законодательного собрания Приморского Края [Электронный ресурс]. URL: http://www.zspk.gov.ru/deputy/ (дата обращения: 03.04.2021).

17. Сайт Законодательной думы Хабаровского края [Электронный ресурс]. URL: http://www.duma.khv.ru/?a=270100566 (дата обращения: 03.04.2021).

18. Сайт Магаданской областной думы [Электронный ресурc]. URL: https://www. magoblduma.ru/elector/dep/ (дата обращения: 03.04.2021).

19. Сайт Народного Хурала Республики Бурятия [Электронный ресурс]. URL: https://hural-buryatia.ru/deputat/ (дата обращения: 03.04.2021).

20. Сайт Сахалинской областной думы [Электронный ресурc]. URL: http://www. dumasakhalin.ru/general-data/deputys?page=1 (дата обращения: 03.04.2021).

21. Туровский Р.Ф. Национализация и регионализация партийных систем: подходы к исследованию // Полития. 2016. №1 (80). С. 162-180.

22. Шпагин С.А. Региональные партийные системы в современной России: к методологии исследования // Вестнник Томского государственного университета. Философия. Социология. Политология. 2012. № 3 (19). С.134-142.

23. Shugart M.S., Carey J.M. Presidents and Assemblies. Constitutional design and electoral dynamics. Cambridge: Cambridge univ. press, 1992. 316 p.

\section{Транслитерация по ГОСТ 7.79-2000 система Б}

1. Budaev B.S. Badmatsyrenov T.B. Politicheskie partii "novykh" sub"ektov Dal'nevostochnogo Federal'nogo okruga v preddverii nachala novogo ehlektoral'nogo tsikla" // Vestnik ZabGU. 2021. Tom 27. № 2. S. 83-96.

2. Budaev B.S. Badmatsyrenov T.B. Politicheskie partii i "dlinnyj ehlektoral'nyj tsikl v Respublike Buryatiya 2016-2019 // Vestnik ZabGU. 2020. Tom 26. № 4. S. 48-59.

3. Grigor'eva M.V. Uchastie regional'nykh i munitsipal'nykh deputatov v vyborakh zakonodatel'nykh sobranij sub"ektov RF // Vestnik Permskogo universiteta. Seriya: Politologiya. 2012. №3. S 13-28.

4. Deputaty Gosudarstvennoj Dumy RF [EHlektronnyj resurs]. URL: http://duma. gov.ru/duma/deputies/ (data obrashheniya: 03.04.2021).

5. Deputaty Soveta Federatsii RF [EHlektronnyj resurs]. URL: http://council.gov.ru/ structure/members/ (data obrashheniya: 03.04.2021).

6. Zaznaev O.I. Izmerenie prezidentskoj vlasti // Uchenye zapiski Kazanskogo gosudarstvennogo universiteta. Gumanitarnye nauki. 2005. Tom 147. kn. 1. S. 4-22.

7. Zaznaev O.I. Indeksnyj analiz poluprezidentskikh gosudarstv Evropy i postsovetskogo prostranstva // Polis. 2007. № 2. S. 146-164.

8. Isaev B.A. KHarakteristiki partijnykh sistem i vychislenie nekotorykh pokazatelej partiom // POLITEHKS. 2016. № 1. S. 29-51.

9. Lejpkhart A. Partijnye sistemy. Dvukhpartijnye i mnogopartijnye sistemy // Partii i vybory: KHrestomatiya / RAN.INION. M.: INION, 2004. S. 28-31.

10. Sajt Gosudarstvennogo sobraniya Il Tumehn Respubliki Sakha YAkutiya [EHlektronnyj resurs]. URL: https://iltumen.ru/deputies (data obrashheniya: 03.04.2021).

11. Sajt Dumy CHukotskogo avtonomnogo okruga [EHlektronnyj resurs]. URL: https://xn--80ahnhajq6aec7b.xn--p1ai/deputaty.html (data obrashheniya: 03.04.2021).

12. Sajt Zakonodatel'nogo sobraniya Amurskoj oblasti [EHlektronnyj resurs]. URL: http://zsamur.ru/section/list/777/9 (data obrashheniya: 03.04.2021).

13. Sajt Zakonodatel'nogo sobraniya Evrejskoj avtonomnoj oblasti [EHlektronnyj resurs]. URL: http://zseao.ru/sostav-i-struktura-zs/deputaty-zakonodatelnogo-sobraniya-vi-sozyva/ (data obrashheniya: 03.04.2021). 
14. Sajt Zakonodatel'nogo sobraniya Zabajkal'skogo kraya [EHlektronnyj resurs]. URL: http://www.zaksobr-chita.ru/sostav-i-struktu-a/deputaty/ (data obrashheniya: 03.04.2021).

15. Sajt Zakonodatel'nogo sobraniya Kamchatskogo kraya [EHlektronnyj resurs]. URL: http://www.zaksobr.kamchatka.ru/events/Deputaty (data obrashheniya: 03.04.2021).

16. Sajt Zakonodatel'nogo sobraniya Primorskogo Kraya [EHlektronnyj resurs]. URL: http://www.zspk.gov.ru/deputy/ (data obrashheniya: 03.04.2021).

17. Sajt Zakonodatel'noj dumy KHabarovskogo kraya [EHlektronnyj resurs]. URL: http://www.duma.khv.ru/?a=270100566 (data obrashheniya: 03.04.2021).

18. Sajt Magadanskoj oblastnoj dumy [EHlektronnyj resurs]. URL: https://www.magoblduma.ru/elector/dep/ (data obrashheniya: 03.04.2021).

19. Sajt Narodnogo KHurala Respubliki Buryatiya [EHlektronnyj resurs]. URL: https:/hural-buryatia.ru/deputat/ (data obrashheniya: 03.04.2021).

20. Sajt Sakhalinskoj oblastnoj dumy [EHlektronnyj resurs]. URL: http://www.dumasakhalin.ru/general-data/deputys?page=1 (data obrashheniya: 03.04.2021).

21. Turovskij R.F. Natsionalizatsiya i regionalizatsiya partijnykh sistem: podkhody k issledovaniyu // Politiya. 2016. №1 (80). S. 162-180.

22. SHpagin S.A. Regional'nye partijnye sistemy v sovremennoj Rossii: k metodologii issledovaniya // Vestnnik Tomskogo gosudarstvennogo universiteta. Filosofiya. Sotsiologiya. Politologiya. 2012. №3 (19). S.134-142.

23. Shugart M.S., Carey J.M. Presidents and Assemblies. Sonstitutional design and electoral dynamics. Cambridge: Cambridge univ. press, 1992. 316 p.

Будаев Б. С. Институциональный параметр "силы" региональных отделений всероссийских партий в Дальневосточном федеральном округе.

На основе анализа данных о партийном распределений полномочий в исполнительных и законодательных органах власти субъектов Дальневосточного Федерального округа, а также представителей субъектов в Федеральном Собрании России, автором оценена "сила" партий в регионах. Оценка "силы" партий осуществлена на основе интервального метода, предложенного М.С. Шугартом и Дж. Кәри. Выявлены основные институциональные характеристики, выделяющие те или иные случаи. Автором предпринята попытка оценить возможный уровень накала идеологической борьбы накануне выборов депутатов Государственной Думы России.

Ключевые слова: политические партии в регионах ДФО России, "сила партий", региональные парлаленты

Budaev B. S. The institutional parameter of the "strength" of regional branches of all-Russian parties in the Far Eastern Federal District.

Based on the analysis of data on the party distribution of powers of the executive and legislative bodies of power of the subjects of the Far Eastern Federal District, as well as representatives of the subjects in the Federal Assembly of Russia, the author assessed the "strength" of parties in the regions. The evaluation of the "strength" of the parties was carried out on the basis of the interval method proposed by Shugart M.S., and Carey J.M. The main institutional characteristics that distinguish certain cases have been identified. The author made an attempt to assess the possible level of intensity of the ideological struggle on the eve of the elections of the deputies of the State Duma of Russia.

Key words: political parties in the regions of the Far Eastern Federal District of Russia, "The strength of the parties", regional parliaments

Для цитирования: Будаев Б. С. Институциональный параметр "силы" региональных отделений всероссийских партий в Дальневосточном федеральном округе // Ойкумена. Регионоведческие исследования. 2021. №3. C. 126-133. DOI: 10.24866/1998-6785/2021-3/126-133

For citation: Budaev B. S. The institutional parameter of the "strength" of regional branches of all-Russian parties in the Far Eastern Federal District // Ojkumena. Regional researches. 2021. № 3. P. 126-133. DOI: 10.24866/1998-6785/2021-3/126-133 